\title{
OS DESAFIOS DA RECUPERAÇÃO DE ÁREAS DEGRADADAS POR REGENERAÇÃO NATURAL
}

\section{Jose de Nazaré Oliveira da Silva Filho'; Mirian Militão Cardoso²; Paloma Garcia Braga ${ }^{3}$.}

${ }^{1}$ Graduando, Universidade Federal Rural da Amazônia (UFRA), Belém, Pará, ${ }^{2}$ Graduando, Universidade Federal Rural da Amazônia (UFRA), Belém, Pará, ${ }^{3}$ Graduando, Universidade Federal Rural da Amazônia (UFRA), Belém, Pará.

DOI: 10.47094/ICONNECA.2021/23

\section{RESUMO}

A regeneração natural é a forma mais natural para a renovação de povoamentos florestais que foram degradados ao longo do tempo. Entretanto, algumas divergências ainda se encontram presentes para que esse método ocorra de forma rápida e eficaz, dependendo do grau de deterioração de determinadas áreas. Visando a recuperação de áreas degradadas, o trabalho consistiu na obtenção de referências em torno da recuperação por regeneração natural, onde estudos apontam maior dificuldade de sua ocorrência em áreas de atividade agropecuária. Por meio da compreensão dos processos que dificultam os mecanismos de tal método, além da forma natural, foram recomendadas a utilização de intervenção humana com técnicas de fácil aplicação.

PALAVRAS-CHAVES: Regeneração natural. Degradação. Sucessão.

ÁREA TEMÁTICA: Recuperação de Áreas Degradadas.

\section{INTRODUÇÃO}

De acordo com a constituição brasileira, todo cidadão possui o direito de viver em um ambiente ecologicamente equilibrado, cabendo ao poder público em conjunto da população o dever de defendêlo e preservá-lo para que as presentes e futuras gerações também possam usufruir (BRASIL, 1990). Uma vez que é imprescindível um meio ambiente sadio para a manutenção e qualidade de vida dos seres vivos.

Em virtude disso, ao observar os adventos ambientais que assolam o planeta, percebe-se que o número de hectares devastados de caráter natural e/ou antrópico é alarmante. A recuperação de um ecossistema degradado requer muito estudo e desafio para que o objetivo seja alcançado.

No que se refere às degradações antrópicas, existem ações de maiores influências negativas para a regeneração natural, tais como a prática do pastoreio de bovinos, roçadas e ocorrência de incêndio. Para este propósito, existem duas principais formas de recuperar as áreas degradadas, especificamente, através da regeneração natural ou do reflorestamento (FÁVERO, 2008). 
Em concordância com Simonelli (2021) sobre recuperação por regeneração natural, a presença de gados na área, danificam as plântulas em desenvolvimento de modo a eliminar do subbosque da floresta. Posteriormente, outro desafio é a ocorrência do fogo, dado que existem estudos que comprovam que em uma área já danificada por queimadas, mesmo que tenha se passado anos, o avanço da regeneração continua sendo difícil, tornando-se o fator mais problemático.

Tais impactos acarretam severas consequências ao ecossistema, pois ocasionam a redução das propriedades e características naturais do meio afetado, acarretando deteriorações, sejam de natureza química, física ou biológica. Além disso, a degradação das áreas causam inúmeros impactos prejudiciais à saúde dos seres vivos, por motivo da contaminação dos rios, solos e ar e por conseguinte, prejudicando a qualidade de vida (KOHLRAUSCH, 2015).

Desta maneira, o presente estudo objetivou analisar as recentes publicações e apresentar contextos dos desafios identificados na recuperação de áreas degradadas através de regeneração natural, além das causas e consequências de tais.

\section{METODOLOGIA}

Este trabalho foi desenvolvido seguindo uma revisão integrativa da literatura, a partir de artigos publicados em revistas científicas da área de Recuperação de Áreas Degradadas que pudessem contribuir para os resultados deste estudo. Recorreu-se a uma busca nas bases de dados Google Acadêmico e Portal de periódicos CAPES.

\section{FUNDAMENTAÇÃO TEÓRICA}

De acordo com Lira et al. (2016), as alterações nos ecossistemas em todo mundo por atividades humanas são importantes fatores para a degradação. Esses danos, são resultados de grandes extensões de florestas devastadas pelo avanço do processo de urbanização ou atividades agropecuárias. $\mathrm{Na}$ ecologia, o ecossistema utiliza mecanismos para retornar as suas condições originais após sofrer danos causados de maneira natural ou por ação humana, conhecido como regeneração natural.

A regeneração natural ocorre no processo de sucessão natural, por meio da germinação de sementes dormentes no solo, fontes de propágulos, dispersão de sementes e rebrotas de tecidos vegetais quando em condições favoráveis, em que tais condições dependem do grau de danos causados ao local e a vegetação remanescente (FRAGOSO et al., 2017).

De acordo com Simonelli (2021), em relação aos desafios da recuperação, quanto mais afastadas as áreas que estão passando por regeneração natural das florestas que são provedoras de propágulos, mais lento será o processo para se regenerar. Isto ocorre devido ao fato de que para uma área se regenerar, é necessário um estímulo natural ou a intervenção humana. Para o estímulo natural, 
os propágulos que são os fragmentos de um vegetal capaz de se propagar, se transportam das florestas matrizes através do ar, até chegar nas áreas degradadas que estão próximas. O transporte desses fragmentos pelo ar ocorre na presença de vento ou pequenos redemoinhos.

Outra forma de estímulo natural é a existência de bancos de sementes presentes no solo, ocorre quando a área foi degradada recentemente, porém no solo ainda existe propágulos vegetativos e sementes, sendo assim, ocorre germinação permitindo o nascimento e desenvolvimento dos vegetais (SIMONELLI, 2021). A sucessão natural é definida como alterações de um ecossistema, e é dividida em sucessão primária onde se encontram os habitats recém formados e a sucessão secundária composta por comunidades formadas a partir de algum distúrbio após a existência da sucessão primária. $\mathrm{Na}$ sucessão secundária, quando iniciada a partir de perturbação, a forma de proceder ocorre com o surgimento de espécies vegetais diferentes comparadas as espécies pioneiras (MESQUITA et al., 2001).

Áreas que foram usadas para agricultura, passam pelo processo de regeneração com maior dificuldade em decorrência de processos de queima e roçadas por longos anos no local. Em vista disso, se encontram vulneráveis a existência plantas exóticas, como a Cecropia (WILLIAMSON et al., 2012). Outra espécie problema é a acácia-negra, que entre suas capacidades biológicas de se tornar invasora, se evidencia a sua floração em 2 anos, farta produção de sementes a partir dos 5 anos, dormência das sementes e facilidade de adaptação a vários ambientes (MOCHIUTTI et al., 2008). Além da presença de espécies arbóreas exóticas, é comum a existência de gramíneas e plantas com alelopatia, dificultando a regeneração e espécies nativas.

Para um resultado satisfatório da regeneração natural, quando necessário, é possível a utilização da intervenção humana através de técnicas de fácil aplicação. A utilização de espécies florestais nativas através da nucleação é uma forma eficaz para o início da sucessão, de modo a evitar o alto custo de implantação. O uso entre 20 a 30 espécies é o suficiente para se iniciar o processo de sucessão, levando em consideração a importância de selecionar espécies capazes de consorciar com espécies pioneiras de ciclo curto (ANDRADE et al., 2018).

A imagem abaixo é exemplo de recuperação por regeneração natural no estado do Espírito Santo, no qual é apresentado uma unidade amostral recuperada em diferentes anos. Este resultado demonstra que a regeneração natural é um processo que consiste em deixar que o dinamismo natural dos vegetais atue livremente, quando há condições. 
Figura 1: Ano: 1975. Polígono delimitando uma área ocupada por gramíneas / Ano: 2007/2008. Polígono delimitando uma área ocupada por florestas.

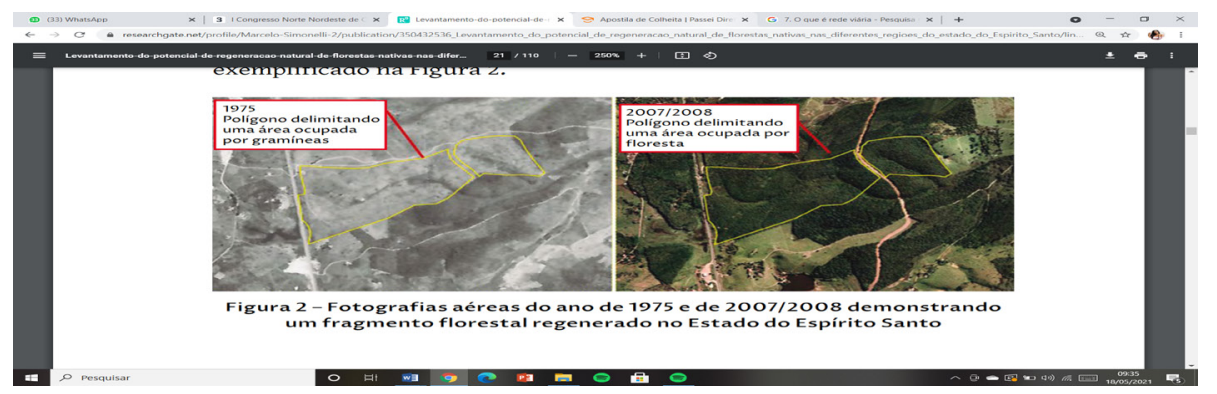

Fonte: SIMONELLI, M.; MARTINS, S.V.; SARTORI, M.; RAPOSO FILHO, F. L.; DADALTO, G.; PEREIRA, M. L. Levantamento do potencial de regeneração natural de florestas nativas nas diferentes regióes do estado do Espírito Santo. 1. ed. Vitória, ES: EDIFES, 2021. 110p.

\section{CONSIDERAÇÕES FINAIS}

Tendo vista dos argumentos apresentados, esse trabalho permitiu verificar o processo da regeneração natural em áreas que sofreram algum tipo de degradação e seus desafios enfrentados. Observou-se que a prática do pastoreio de bovinos, roçadas e ocorrência de incêndio acarretam danos mais severos e maiores dificuldades na recuperação da área degradada.

Entende-se também que, algumas espécies exóticas se adaptam facilmente em áreas que já sofreram deterioração, dificultando a existência de espécies nativas no local. Neste sentido, em algumas situações faz-se necessário a intervenção humana para ajudar na recuperação com técnicas facilitadoras, como a nucleação para assistir a colonização de espécies na área comprometida.

\section{PRINCIPAIS REFERÊNCIAS}

BRASIL. [Constituição (1988)]. Constituição da República Federativa do Brasil de 1988: promulgada em 5 de outubro de 1988. 4. Ed. São Paulo: Saraiva,1990.

KOHLRAUSCH, F.; JUNG, C. F. Áreas ambientais degradadas: causas e recuperação. In: Congresso Nacional de Excelência em Gestão. Rio de janeiro, 2015.

FÁVERO, C.; LOVO, I. C.; MENDONÇA, E. DE SÁ. Recuperação de área degradada com sistema agroflorestal no vale do Rio Doce, Minas Gerais. Revista Árvore, Viçosa, v. 32, n. 5, p. 861-868, 2008.

LIRA, D. F. DE SOUZA; MARANGON, L. C.; MARANGON, G. P.; SILVA, E. A.; LONGHI, R. V. Análise da estrutura de uma área em processo de recuperação contendo o modelo de Indução e condução da regeneração natural, na barragem do Rio Siriji, Vicência - PE. Agropecuária Científica no Semiárido, Patos - PB, v. 12, n. 3, p. 287-294, jul-set, 2016. 
FRAGOSO, R. DE OLIVEIRA.; CARPANEZZI, A. A.; KOEHLER, H. S.; ZUFFELLATO-RIBAS, $\mathrm{K}$. C. Barreiras ao estabelecimento da regeneração natural em áreas de pastagens abandonadas. Ciência Florestal, Santa Maria, v. 27, n.4, p. 1451-1464, out.-dez., 2017.

MESQUITA, R.C.G.; ICKES, K.; GANADE, G.; WILLIAMSON, G.B. Alternative succesional pathways in the amazon basin. Journal of Ecology, v. 89, p. 528-537, 2001.

WILLIAMSON, G.B.; BENTOS, T. V.; LONGWORTH, J.B.; Mesquita, R.C.G. Convergence and divergence in alternative successional pathways in Central Amazonia. Plant Ecology \& Diversity, v. 7, p. 341-348, 2012.

MOCHIUTTI, S.; HIGA, A. R.; SIMON, A. A. Fitossociologia dos estratos arbóreo e de regeneração natural em um povoamento de acácia-negra (acacia mearnsii de wild.) Na região da floresta estacional semidecídual do rio grande do sul. Ciência Florestal, Santa Maria, v. 18, n. 2, p. 207222, abr.-jun., 2008.

ANDRADE, G. K. O.; FERREIRA, R. A.; FERNANDES, M. M.; SILVA, T. R.; SOUZA, I. B. A.; MAGALHÃES, J. S. Regeneração natural em área de reflorestamento misto com espécies nativas no município de Laranjeiras, SE. Revista de Ciências Agrárias, Sergipe, v. 61, 2018. 